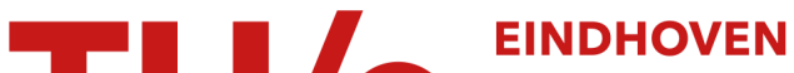 \\ UNIVERSITY OF \\ TECHNOLOGY
}

\section{Two-dimensional hybrid materials : transferring technology from biology to society}

Citation for published version (APA):

Leroux, F., Rabu, P., Sommerdijk, N. A. J. M., \& Taubert, A. (2015). Two-dimensional hybrid materials : transferring technology from biology to society. European Journal of Inorganic Chemistry, (7), 1089-1095. https://doi.org/10.1002/ejic.201500153

DOI:

10.1002/ejic.201500153

Document status and date:

Published: 01/03/2015

Document Version:

Publisher's PDF, also known as Version of Record (includes final page, issue and volume numbers)

Please check the document version of this publication:

- A submitted manuscript is the version of the article upon submission and before peer-review. There can be important differences between the submitted version and the official published version of record. People interested in the research are advised to contact the author for the final version of the publication, or visit the $\mathrm{DOI}$ to the publisher's website.

- The final author version and the galley proof are versions of the publication after peer review.

- The final published version features the final layout of the paper including the volume, issue and page numbers.

Link to publication

\section{General rights}

Copyright and moral rights for the publications made accessible in the public portal are retained by the authors and/or other copyright owners and it is a condition of accessing publications that users recognise and abide by the legal requirements associated with these rights.

- Users may download and print one copy of any publication from the public portal for the purpose of private study or research.

- You may not further distribute the material or use it for any profit-making activity or commercial gain

- You may freely distribute the URL identifying the publication in the public portal.

If the publication is distributed under the terms of Article $25 \mathrm{fa}$ of the Dutch Copyright Act, indicated by the "Taverne" license above, please follow below link for the End User Agreement:

www.tue.nl/taverne

Take down policy

If you believe that this document breaches copyright please contact us at:

openaccess@tue.nl

providing details and we will investigate your claim. 


\title{
Two-Dimensional Hybrid Materials: Transferring Technology from Biology to Society
}

\author{
Fabrice Leroux, ${ }^{*[a]}$ Pierre Rabu, ${ }^{*[b]}$ Nico A. J. M. Sommerdijk, $*[c]$ \\ and Andreas Taubert*[d]
}

\begin{abstract}
Hybrid materials are at the forefront of modern research and technology; hence a large number of publications on hybrid materials has already appeared in the scientific literature. This essay focuses on the specifics and peculiarities of hybrid materials based on two-dimensional (2D) building blocks and confinements, for two reasons: (1) 2D materials have a very broad field of application, but they also illustrate many of the scientific challenges the community faces, both on a fundamental and an application level; (2) all authors of this essay
\end{abstract}

are involved in research on 2D materials, but their perspective and vision of how the field will develop in the future and how it is possible to benefit from these new developments are rooted in very different scientific subfields. The current article will thus present a personal, yet quite broad, account of how hybrid materials, specifically 2D hybrid materials, will provide means to aid modern societies in fields as different as healthcare and energy.

\section{Introduction}

Hybrid materials are at the heart of today's science and technology. To match the ever-growing need of our modern society for tools addressing pressing issues regarding health, environment and toxicology, energy, and communication, advanced materials with enhanced properties are among the key enablers advancing all modern technologies. Hybrid materials in particular combine the advantages of two (or more) different materials, often drawing their strength from the synergistic combination of seemingly incompatible components. This yields advanced materials for virtually every field of modern society. Quite some of the designs of modern hybrid materials were either found in nature prior to fabricating their synthetic equivalents. Moreover, analogues of already existing synthetic materials were discovered after

[a] Inorganic Materials, Institut de Chimie de Clermont-Ferrand (ICCF) - UMR CNRS 6296, Université Blaise Pascal, Chimie 5, Campus des Cézeaux, 24 avenue des Landais BP 8002663171 Aubière Cedex, France E-mail: Fabrice.Leroux@univ-bpclermont.fr http://iccf.univ-bpclermont.fr/spip.php?article166

[b] Institut de Physique et Chimie des Matériaux de Strasbourg (IPCMS), UMR7504 CNRS - Universite de Strasbourg, 23 Rue du Loess, F-67034 Strasbourg, France E-mail: Pierre.Rabu@ipcms.unistra.fr http://www.ipcms.unistra.fr/?page_id=11205

[c] Department of Chemical Engineering and Chemistry and Institute for Complex Molecular Systems, Eindhoven University of Technology, P.O. Box 513, NL-5600 MB Eindhoven, The Netherlands E-mail: n.sommerdijk@tue.nl http://www.biomineralization.nl/general/our_group/tue.html

[d] Institute of Chemistry, University of Potsdam, Karl-Liebknecht-Str. 24-25, D-14476 Potsdam, Germany E-mail: ataubert@uni-potsdam.de www.taubert-lab.net the synthetic hybrid materials had been developed. This illustrates a clear, although often unexpected, link between materials design in the biological and the technological worlds.

This link can be exploited for the development of advanced (multi)functional hybrid materials with application potential in virtually all fields relevant to a modern society. Examples include, but are not limited to, health (implants, drug delivery, surgical tools, etc.), energy (batteries, fuel cells, solar cells, water splitting, reflective or antireflective coatings, etc.), transportation (lightweight construction, antireflective coatings, low friction surfaces, etc.), or information technology (magnetic and optical data storage, information transfer, optical fibers, etc.). A previous review has categorized the application areas for polymer-inorganic supramolecular nanohybrids using a color code: red for nanohybrids related to the life science and healthcare sectors, white for energy and environmental applications, green for applications related to agriculture and food, and blue for aqua and marine applications. ${ }^{[1]}$ Another recent review has highlighted possible synthetic strategies for $2 \mathrm{D}$ nanosheet-based hybrid materials and has specifically explored applications for energy and environmental technologies through lattice engineering techniques resulting in $2 \mathrm{D}$ platelet hybridization. ${ }^{[2]}$ Additionally, several journals have published special issues dedicated to hybrid materials in a broader sense $\mathrm{e}^{[3]}$ or in a more specific manner such as application aspects specific to materials based on layered double hydroxides (LDHs). ${ }^{[4]}$ The fact that several scientific journals have already assembled special issues on the applications of hybrid materials clearly illustrates the high interest these materials attract. 
Besides a widespread application potential, however, hybrid materials are very interesting and challenging from a fundamental point of view. For example, it is still difficult to (1) design a priori a hybrid material with a preprogrammed set of properties, (2) develop a complete vision of the countless numbers of possible hybridizations by $2 \mathrm{D}$ lattice engineering, or (3) comprehend the possibilities of a given pool of hybrid materials for transporting active ingredients. Another point, both fundamentally and technologically important, is the development of addressable materials, stimuli-responsive materials, and materials that respond to more than one change in the environment or materials that can perform mechanical work.

While clearly some interesting and promising materials have been developed, hybrid materials have only begun to make their way into the broader fields of science and technology. This is, for example, illustrated by the increasing number of international conferences on the topic, by the yearly increasing number of publications containing the term "hybrid materials", or by the increasing number of research groups devoting their activities to the subject.

The purpose of the current article is not to provide an exhaustive summary of existing hybrid materials or a complete overview of trends and new developments; rather it is a focused selection of some developments that the authors believe to be key for the further development of the field. Naturally, the selection of the articles and subjects cited here and the ideas developed throughout the article are biased by the authors' interests and backgrounds. One notable point is the focus on two-dimensional (2D) materials. This is not to say that only $2 \mathrm{D}$ materials are promising; the rather mundane explanation is that all authors have a significant interest in 2D materials. In the remainder of the essay, we will therefore discuss what we see as promising perspectives for the upcoming developments in functional 2D materials.

\section{From Biology to Materials and Vice-Versa}

Biominerals such as bones, teeth, and seashells are biological hybrid materials in which well-defined interactions between organic and mineral components lead to a hierarchical organization of inorganic nanoparticles with precisely controlled size, shape, and crystallinity. ${ }^{[5]}$ The structural precision of biominerals often leads to advanced physical (mechanical, ${ }^{[6]}$ optical, ${ }^{[7]}$ magnetic ${ }^{[8]}$ ) properties tailor-made to their function. These remarkable products are a source of inspiration for many scientists, for their structure, their functionality, as well as for the way they are produced. Indeed, translating biological formation pathways into chemical strategies towards organic-inorganic hybrid and nanomaterials holds great promise for the development of "green" production routes to designer materials with advanced properties. ${ }^{[9]}$

The best known example is the nacre of the mollusk shell (mother of pearl), which consists of a brick-and-mortar arrangement of aragonite (a polymorph of $\mathrm{CaCO}_{3}$ ) and a biomolecular organic matrix. The organic matrix not only provides the nacre with the mechanical properties that make it stand out from the brittle aragonite platelets, the biological matrix also controls the nucleation and growth of the mineral, dictating the orientation of the crystals as well as their shape.

The organization and mechanical properties of nacre have inspired many scientists to emulate its structure through the formation of layered organic-inorganic composites from prefabricated components, in many cases with impressive properties. ${ }^{[10]}$ However, these top-down assembly methods do not achieve the perfection observed in the natural material; hence understanding the secret of the bottom up self-assembly as used in biological systems may lead to improved control over structure and properties in synthetic hybrid materials.

As the mineralization process in nacre starts off with the oriented nucleation of calcium carbonate on a biopolymer surface, many efforts have been spent in understanding the interplay between the organic and inorganic components at the very early stages. Already in the 1980s Addadi and Weiner proposed that nucleation of calcium carbonate was induced on a surface consisting of a sulfated carbohydrate matrix acting as a calcium sponge within which an aspartic acid rich template exposing an ordered array of carboxylate groups directed the orientation of the crystals. ${ }^{[1]}$ Many follow-up studies investigated the hard-soft interactions during the templating process using model systems such as Langmuir monolayers ${ }^{[12]}$ and self-assembled monolayers (SAMs). ${ }^{[13]}$ These studies showed that, although epitaxial relations between template and mineral may play a role, they are not a strict requirement, ${ }^{[14]}$ and moreover that the mutual adaptation of template and mineral make it difficult to predict the outcome of the nucleation process. ${ }^{[15]}$ Another important insight into biomineralization mechanisms was the realization that many biological crystals are formed through an amorphous precursor phase that was first deposited within the templating structure and molded into the desired shape before crystallization occurs. ${ }^{[16]}$ This principle was soon exploited for the production of crystals with predesigned nonequilibrium morphologies, ${ }^{[17]}$ while cryoTEM investigation of a mineralizing Langmuir monolayer demonstrated how structural information from a template could be used to direct the amorphous-to-crystalline transition to yield oriented crystals. ${ }^{[18]}$ And, although macroscopically this transition occurs through a dissolution-reprecipitation mechanism, it was demonstrated that on a microscopic scale the conversion can occur through a direct solid-state transformation, ${ }^{[19]}$ as is also suggested for biological systems. ${ }^{[20]}$ Recently, liquid-phase TEM - which allows the visualization of the dynamic interplay between organic and inorganic components in real time and with nanometer resolution - was used to probe the role of sulfated biomacromolecules using sulfonated polystyrene as a model system. ${ }^{[21]}$ This study revealed the role of the polymeric "ion sponge" in controlling nucleation such that amorphous material rather than one of the crystalline polymorphs is formed. 
Similar hypotheses have been proposed by several other studies. ${ }^{[22]}$

With inspiration from biomineralization, organic-inorganic interactions at interfaces have been explored for the formation of $2 \mathrm{D}$ hybrids based on other biominerals such as calcium phosphate ${ }^{[23]}$ or magnetite, ${ }^{[24]}$ but also many studies have extended this approach to controlling the formation of typical engineering materials such as $\mathrm{CdS}, \mathrm{ZnS}$, $\mathrm{PbS}, \mathrm{CdSe}, \mathrm{TiO}_{2}$, as well as $\mathrm{Au}, \mathrm{Ag}$, and $\mathrm{Pt}$ nanoparticles. ${ }^{[25]}$ In particular, from an application point of view it is interesting to point out that the formation of ordered assemblies of crystals with near-uniform sizes, shapes, and orientation as observed in the prismatic layer of the mollusk shell does not require a very precise templating structure. ${ }^{[26]}$ Rather, these well-defined crystal assemblies are formed in a minimalistic approach in which uniformity results from competition driven by thermodynamic principles and which would relax the requirements for the bioinspired synthesis of advanced 2D hybrid materials. ${ }^{[27]}$

In addition to the growth of 2D materials by several organisms, we can point out that $2 \mathrm{D}$ minerals are now thought to have possibly played a key role in the development of organisms in the early life evolution period. So the clays, a large class of 2D minerals, provided high fidelity of preservation of microfossils over billion years. ${ }^{[28]}$ This remarkable preservation stems from the intrinsic stability and adsorption properties of clays combined with microbial metabolisms helping catalysis of a wide range of aluminosilicates. In fact, the clays are widespread on the earth and they act as natural ion exchangers in a wide $\mathrm{pH}$ range. Their ability to adsorb multiple molecules, thus confined in the interlamellar space, and their catalytic properties make them microreactors of choice for prebiotic chemistry. Series of prebiotic synthons such as amino acids, oligopepetides, or oligonucleotides have been synthetized in the presence of clays. ${ }^{[29-31]}$ Clays were also shown to catalyze RNA polymerization and favor the formation fatty acid vesicles used as protocell models. ${ }^{[32]}$ Yet, the issue remains that biomolecules were most likely diluted in oceans, rivers, or lakes. Hence, in the absence of confinement by cell membranes, as observed in contemporary life, appropriate systems should form to provide concentration of solutes, confinement for biochemical reactions, and stability under environmental conditions. The recent work by Luo et al. ${ }^{[33]}$ indicates that clays can form hydrogels in ocean water, thanks to peculiar electric charge distribution throughout the clay nanoplatelet particles. Moreover, their data shows that RNA is efficiently protected and RNA synthesis is enhanced by the clay hydrogel environment. Although still controversial, these studies demonstrate that clay-based bioinorganic hybrid systems organized in hydrogels constitute plausible reaction media for early life evolution, thanks to synergy between components.

The return of synthetic materials toward biology mostly involves the general field of health. Probably one of the best known examples pioneered by Choy's group concerns the possibility to incorporate nucleotides including DNA in between LDH nanosheets and form some kind of vehicle that protects the living macromolecule from catalytic and thermal degradation. ${ }^{[34]}$ To explain such structural compatibility, the conformation of DNA was found to match the interlayer topology with the phosphate backbone groups aligned with aluminum lattice positions. ${ }^{[35]}$ Once again, the enhanced stability supplied by the organoceramic material is surmised to have played a key role in prebiotic evolution when the earliest life forms were exposed to harsh thermal conditions.

Largely extended for various applications, which includes drug delivery for gene therapy, such a container may also be used for astringent properties in patch or in body cream or as taste-masking as for ibuprofen. ${ }^{[36]}$ The trend is to develop new ways in drug "self-delivery" (mostly triggered by $\mathrm{pH}$ ) in physiologic medium; this concerns all fields of human health covering anti-inflammatory, antalgic, antitumor, etc. agents. ${ }^{[37]}$ Very elegant approaches have been recently described showing excellent anticancer performance in photodynamic therapy using a supramolecular photosensitizer fabricated by the incorporation of zinc phthalocyanines $(\mathrm{ZnPc})$ into the galleries of $\mathrm{LDHs}^{\left[{ }^{[38]}\right.}$ This is due to a high singlet oxygen production efficiency that was already shown for hybrid LDHs using porphyrin-based molecules. ${ }^{[39]}$ Other significant breakthroughs in using LDHs as advanced drug-delivery nanomaterials with a high biocompatibility have recently demonstrated their feasibility as a nanocarrier injectable directly into blood. ${ }^{[40]}$ In addition to the inertness of LDH nanomaterials in the blood plasma, resulting in an interesting hematocompatibility for further development, such nanovehicles may overcome the drawback of active ingredients such as the chemotherapeutic agent methotrexate (MTX), limited by its short plasma half-life and its subsequent high dosage required for cancer cell suppression. ${ }^{[41]}$ The MTX-LDH nanohybrid exhibited a superior targeting effect resulting in high antitumor efficacy compared to MTX alone, as well as a superior efficacy profile in inhibiting tumor proliferation and in provoking the induction of apoptosis, thus resulting in significant survival benefits. Importantly MTX-LDH nanocarriers did not accumulate in any specific tissue nor cause acute toxicity, underlining their great potential as an anticancer drug with enhanced in vivo antitumor activity and bioavailability in target tumor tissue along with reduced side effects. ${ }^{[42]}$

\section{From Geology to Materials}

As modern science and society are strongly biology- and health-driven, one occasionally forgets that besides the living nature there is also the vast world of geological species that often have equally interesting properties. Examples include zeolites, clays, or double hydroxides, all of which now exist as geological samples, but have also been made in the laboratory. The laboratory is, in fact, sometimes the "more versatile nature" in the sense that synthetic approaches enable the synthesis of new compounds that do not exist in nature, for example in the field of zeolites or LDHs. 
This is largely illustrated by the polymer nanocomposite (PN) field, where nanofillers try to endow the polymer with enhanced properties thus rendering it possibly multifunctional. In contrast to the microcomposite, the benefit of PNs resides in the highly pronounced interface that is permitted by manipulating single platelets. Such engineering 2D nanotechnology may be used for further hybridization between nano building blocks to lead to interesting features in the domain of energy and optoelectronics (see below). As far as PNs are concerned, very specific properties should be integrated to respond both to the restriction in chemicals regarding toxicity and to the sustainability preferring the biosourced polymer over that from fossil extraction. Straightforward properties such as polymer protection from oxidation (using UV-stabilizers and radicals scavengers) are probably by now in the technological step unless synergistic effects may be found with the container. Regarding toxicity, the replacement of, for instance, brome-reducing flame (BRF) and chromate agents prompts new developments where 2D hybrid materials may play a key role as filler due to their barrier effect coming not only from their structural anisotropy but also from their cargo effect. This is exemplified by flame retardant PNs using LDH in replacement of $\mathrm{BRF}^{[43]}$ and by corrosion inhibitors placed into the polymer coating to protect metal substrate. ${ }^{[4]}$ Fillers usually endow properties to the polymer, but the opposite is also true. Using self-assembly of triple building blocks, LDH nanoplatelets, polyvinyl alcohol (PVA), and quantum dots (QDs: CdTe or $\mathrm{CdSe} / \mathrm{ZnS}$ ), flexible films were fabricated that were found to be highly luminescent (strong fluorescence and high fluorescence quantum yield) with finely tunable fluorescence (green, yellow, orange, and red) as well as a high photo- and thermostability. ${ }^{[45]}$

\section{Energy Conversion Devices and Functional Materials}

Thanks to great efforts in fabricating nanosheets as building blocks, new developments have been recently launched. For instance, recent studies regarding the preparation of LDH nanosheets through topotactic and/or topochemical reactions permit us now to envision new building strategies such as electrostatically derived reassembling, layer-by-layer deposition, crystal growth on the surface sites of nanosheets (nanofilms), as well as the mixing of an endless number of other structural blocks to yield hybridization, core-shell nanoarchitectures, or possible staging phenomena. ${ }^{[46,47]}$ These 2D nanohybrid materials are investigated for some of today's needs regarding energy as supercapacitors, water splitting for fuel cells, as well as other modern applications regarding optical and magnetic properties.

For instance when graphene ${ }^{[48]}$ or carbon nanotubes ${ }^{[49]}$ are mixed with LDH nanosheets to yield a so-called molecular-scale heteroassembly, high performance supercapacitors are obtained combining both high capacity and high power rate. In the case of $2 \mathrm{D} / 2 \mathrm{D}$ heterostructure, this is explained by the heterostacking of redoxable LDH nanosheets and conductive graphene into a genuine superlattice structure that, as a consequence, improves the charge transfer efficiency, while for the $1 \mathrm{D} / 2 \mathrm{D}$, a quasi-3D architecture is obtained, displaying well-defined core-shell configuration and enlarged surface area. A novel hierarchical and submicroscopic structure combining a $3 \mathrm{D}$ template and a $\mathrm{LDH}$ yields also great pseudocapacitance properties. ${ }^{[50]}$ Hollow LDH nanopolyhedra were synthesized with zeolitic imidazolate framework-67 (ZIF-67) nanocrystals as templates. The nanocages inherit the rhombic dodecahedral shape of the ZIF-67 templates, and the shell was found to be composed of nanosheets assembled with an edge-to-face stacking resulting in LDH nonspherical structure. Aside from the hybridization and the mixing with electrical percolates, another concept consists of producing an intimate mixture from a 2D LDH hybrid assembly by carbonization where the collapse of the inorganic moiety may play the role of porous agent for the carbon replica after acid leaching or may remain partly to supply an additional pseudocapacity. ${ }^{[51]}$

A single layer of nanosheets is of interest in the oxygen evolution reaction, a key reaction in water splitting. ${ }^{[52]}$ More active sites and improved electronic conductivity were demonstrated for $\mathrm{Ni} / \mathrm{Fe}$ and $\mathrm{Ni} / \mathrm{Co} \mathrm{LDH}$ nanosheets, outperforming a commercial iridium dioxide catalyst in both activity and stability. In that same vein, improved chemical stability of photocatalysts is achieved when combining other heterostacking of nanohybrid materials composed of an ordered mesoporous assembly fabricated by a layer-bylayer method between $\mathrm{Zn} / \mathrm{Cr} \mathrm{LDH}$ and layered titanium oxide. ${ }^{[53]} \mathrm{Zn} / \mathrm{Cr}$ was reported as one of the most efficient photocatalysts for visible light water splitting (oxygen generation), due to its high quantum yield (incident photonto-oxygen conversion efficiency at a given wavelength). ${ }^{[54]}$ Additionally the interstratification maintains the excellent photocatalytic activity for visible-light-induced $\mathrm{O}_{2}$ generation; this in association with an electronic coupling between the component nanosheets and a protection of the $\mathrm{LDH}$ lattice by layered titanate. Enhanced photoelectrochemical water splitting was also reported for a hybridization using an aligned hierarchical nanoarray containing a $\mathrm{ZnO}$ core and a LDH nanoplatelet shell synthesized by a facile electrosynthesis method. ${ }^{[55]}$

The capability to exfoliate and restack nanosheets offered by LDH was also exploited to provide original synthetic multiproperty materials. For instance, Coronado and co-workers investigated the recombination of nanosheets obtained from the exfoliation of the magnetic LDH $\left[\mathrm{Ni}_{0.66} \mathrm{Fe}_{0.33}(\mathrm{OH})_{2}\right]\left(\mathrm{NO}_{3}\right)_{0.33}$ and the 2D superconductor $\mathrm{Na}_{0.33}\left[\mathrm{TaS}_{2}\right]$. Actually, they succeeded in restacking a new alternating heterostructure $\left[\mathrm{Ni}_{0.66} \mathrm{Fe}_{0.33}(\mathrm{OH})_{2}\right]\left[\mathrm{TaS}_{2}\right]$, thus combining by design superconductivity and ferromagnetism in one phase. ${ }^{[56]}$ Since then, LDHs incorporating photochromic molecules (such as azobenzene) were found to exhibit interesting photomagnetic or thermomagnetic properties resulting in stimuli-responsive hybrid materials. ${ }^{[57]}$ 
Other hydroxide minerals, layered single hydroxides (LSHs), exhibit a Brucite-like structure of the metal hydroxide nanosheets very similar to that of LDHs. However, in contrast to LDHs, the nanosheets contain only divalent metals, and the counteranions are not "free" in the interlamellar space but participate in the coordination of the metal together with hydroxide ions. Small structural variations may occur, essentially because of the necessary adaptation of the molecular area of each metal ion to the molecular area of the grafted anions or to the formation of tetrahedral sites. ${ }^{[58]}$ Among these minerals, $\mathrm{Cu}^{\mathrm{II}}$ derivatives are particularly under focus due to their peculiar magnetic behavior, like the Kapellasite $\alpha-\mathrm{Cu}_{3} \mathrm{Zn}(\mathrm{OH})_{6}(\mathrm{Cl})_{2}$, the Haydeeite, $\alpha-\mathrm{Cu}_{3} \mathrm{Mg}(\mathrm{OH})_{6} \mathrm{Cl}_{2}$ or $\mathrm{Cu}_{3} \mathrm{Cd}(\mathrm{OH})_{6}\left(\mathrm{NO}_{3}\right)_{2}$, for instance. ${ }^{[59]}$ Instead of lying in the $\mathrm{Cu}^{\mathrm{II}}$ plane, nonmagnetic ions can be found in the octahedral site between two $\mathrm{Cu}^{\mathrm{II}}$ layers. This leads to a triple-deck architecture like that in the Hebertsmithite $\mathrm{Cu}_{3} \mathrm{Zn}(\mathrm{OH})_{6}(\mathrm{Cl})_{2}$ or in $\left(\mathrm{Mg}_{x} \mathrm{Cu}_{1-x}\right) \mathrm{Cu}_{3}$ $(\mathrm{OH})_{6}(\mathrm{Cl})_{2} \cdot{ }^{[60]} \mathrm{In}$ all compounds, the magnetic ions form a Kagomé network, providing real examples of quantum Kagomé antiferromagnetic systems, which are expected to show nonconventional Néel order and are good candidates for the formation of the resonating valence bond (RVB) state at low temperatures.

Despite the coordination of the counteranions (nitrates, acetates, sulfates, chlorides, ...) to the metal sheets, LSHs exhibit, like LDHs, anion exchange properties. The hybridization of LSHs was thoroughly investigated, especially to tune the magnetic interactions within and between the metal hydroxide layers. Series of model compounds were obtained, allowing for comprehensive understanding of the role of interlamellar distance, structural deformation, presence of saturated or conjugated interlamellar bridges $(\pi$ electrons), anisotropy or substitution of simple counteranions by metal complexes onto the magnetic properties of $2 \mathrm{D}$ systems in general. ${ }^{[1]}$ New multiproperty hybrid systems were also obtained combining magnetic and optical properties including magneto-optical compounds, ${ }^{[62]}$ photomagnetic compounds, ${ }^{[63]}$ and magnetochiral materials. ${ }^{[64]}$ All studies on magnetic, optical, conducting 2D hybrid systems highlight the importance of the interface between components on the control of the properties and the possible existence of synergy between properties.

\section{Perspectives}

It is our belief that $2 \mathrm{D}$ hybrid materials will continue to match challenges in terms of the needs of our modern society and the requirement for sustainable development. This can already be seen in different domains concerning health, where inorganic-organic supramolecular architectures show anticancer behavior and are increasingly designed for stimuli-driven and/or theranostic approaches to limit high dosage associated with side-effects. Such multifunctionality (detection and therapy) may be tuned to respond to energy and comfort as in the development of solar energy harvesters (photosensitizers), photocatalysts, electrode materials, and other conversion devices to overcome the "fast-advancing" problem of rarefaction (as for Pt, Ir, $\mathrm{Ru}$, and rare-earth elements among them) as well as to avoid toxic chemicals. Recent hybridization is opening a large range of possibilities. $1 \mathrm{D}, 2 \mathrm{D}$, and $3 \mathrm{D} / 2 \mathrm{D}$ hybridizations yield better performance, as exemplified in energy and water splitting or in the general field of bioinspired materials. Multiple possible combinations suggest that only a part of the iceberg is today uncovered for alternative 2D materials as mentioned in a review article. ${ }^{[65]}$

As far as scale-up is now concerned, "gravel to grave" environmental impact should be considered and the associated life cycle assessment (LCA) should be measured. An idea is to limit fossil resources, but not at the price of reducing the material properties. In that sense, it is known that organic-inorganic hybrid materials may present synergistic effects, i.e. Guest [Host] $>$ Guest + Host, but also in the $\mathrm{PN}$ domain, i.e. Filler [Polymer] $>>$ Polymer, and this can be used to make the biosource polymer as relevant as the thermoplastic obtained from a fossil source. ${ }^{[6]}$ Another big challenge for an eco-friendly development is to limit $\mathrm{CO}_{2}$ impact. By mineralizing atmospheric $\mathrm{CO}_{2}, 2 \mathrm{D}$ materials may partially contribute, but probably regarding the massive production coming from cement and fossil extraction (shale gas), other solutions should be explored.

In another field, molecular electronics is steadily growing in recent years. Here we find the interface issues that are characteristic of hybrid materials. ${ }^{[67]}$ Especially if one considers the recent work on multilayer magnetoresistive devices, there is a significant breakthrough with heterostructures including molecular semiconductor layers (organic or organometallic) used as a tunnel barrier between magnetic electrodes. ${ }^{[68]}$ Such systems seem promising to improve devices for spin electronics. So far, the molecular layers use very simple molecules, usually commercial, but we can predict the development of ad hoc molecules in the near future.

\section{Acknowledgments}

The authors thank the following institutions for their continued financial support: Deutsche Forschungsgemeinschaft, Deutscher Akademischer Austauschdienst, University of Potsdam, Land Brandenburg, Centre National de la Recherche Scientifique (CNRS), University of Strasbourg, International Center for Frontier Research in Chemistry.

[1] D. H. Park, S. J. Hwang, J. M. Oh, J. H. Yang, J. H. Choy, Prog. Polym. Sci. 2013, 38, 1442-1486.

[2] J. L. Gunjakar, I. Y. Kim, J. M. Lee, Y. K. Jo, S. J. Hwang, J. Phys. Chem. C 2014, 118, 3847-3863.

[3] a) J. Mater. Chem. 2010, 20, 9263-9562; b) Appl. Clay Sci. 2014, 100, 1-128.

[4] Recent Pat. Nanotechnol. 2012, 6, 157-248.

[5] a) M. E. Davis, Science 2004, 305, 480-480; b) H. A. Lowenstam, S. Weiner, On Biomineralization, Oxford University Press, Oxford, 1989; c) S. Mann, Biomineralization, Principles and Concepts in Bioinorganic Materials Chemistry, Oxford University Press, Oxford, 2001; d) S. Weiner, L. Addadi, J. Mater. 
Chem. 1997, 7, 689-702; e) F. C. Meldrum, H. Colfen, Chem. Rev. 2008, 108, 4332-4432.

[6] a) B. L. Smith, T. E. Schaffer, M. Viani, J. B. Thompson, N. A. Frederick, J. Kindt, A. Belcher, G. D. Stucky, D. E. Morse, P. K. Hansma, Nature 1999, 399, 761-763; b) S. Kamat, X. Su, R. Ballarini, A. H. Heuer, Nature 2000, 405, 1036-1040; c) A. H. Heuer, D. J. Fink, V. J. Laraia, J. L. Arias, P. D. Calvert, K. Kendall, G. L. Messing, J. Blackwell, P. C. Rieke, D. H. Thompson, A. P. Wheeler, A. Veis, A. I. Caplan, Science 1992, 255, 1098-1105; d) J. Aizenberg, J. C. Weaver, M. S. Thanawala, V. C. Sundar, D. E. Morse, P. Fratzl, Science 2005, 309, 275-278; e) H. J. Gao, B. H. Ji, I. L. Jager, E. Arzt, P. Fratzl, Proc. Natl. Acad. Sci. USA 2003, 100, 5597-5600; f) J. C. Weaver, G. W. Milliron, A. Miserez, K. Evans-Lutterodt, S. Herrera, I. Gallana, W. J. Mershon, B. Swanson, P. Zavattieri, E. DiMasi, D. Kisailus, Science 2012, 336, 1275-1280.

[7] a) J. Aizenberg, A. Tkachenko, S. Weiner, L. Addadi, G. Hendler, Nature 2001, 412, 819-822; b) V. C. Sundar, A. D. Yablon, J. L. Grazul, M. Ilan, J. Aizenberg, Nature 2003, 424, 899-900.

[8] a) R. E. Dunin-Borkowski, M. R. McCartney, R. B. Frankel, D. A. Bazylinski, M. Posfai, P. R. Buseck, Science 1998, 282, 1868-1870; b) S. H. K. Eder, H. Cadiou, A. Muhamad, P. A. McNaughton, J. L. Kirschvink, M. Winklhofer, Proc. Natl. Acad. Sci. USA 2012, 109, 12022-12027; c) S. Staniland, B. Ward, A. Harrison, G. van der Laan, N. Telling, Proc. Natl. Acad. Sci. USA 2007, 104, 19524-19528.

[9] F. Nudelman, N. Sommerdijk, Angew. Chem. Int. Ed. 2012, 51, 6582-6596; Angew. Chem. 2012, 124, 6686.

[10] a) A. Sellinger, P. M. Weiss, A. Nguyen, Y. Lu, R. A. Assink, W. Gong, C. J. Brinker, Nature 1998, 394, 256; b) L. J. Bonderer, A. R. Studart, L. J. Gauckler, Science 2008, 319, 1069; c) P. Podsiadlo, A. K. Kaushik, E. M. Arruda, A. M. Waas, B. S. Shim, J. Xu, H. Nandivada, B. G. Pumplin, J. Lahann, A. Ramamoorthy, N. A. Kotov, Science 2007, 318, 80.

[11] L. Addadi, J. Moradian, E. Shay, N. G. Maroudas, S. Weiner, Proc. Natl. Acad. Sci. USA 1987, 84, 2732-2736.

[12] S. Mann, B. R. Heywood, S. Rajam, J. D. Birchall, Nature 1988, 334, 692-695.

[13] J. Aizenberg, A. J. Black, G. M. Whitesides, Nature 1999, 398, 495-498.

[14] N. Sommerdijk, G. de With, Chem. Rev. 2008, 108, 4499-4550.

[15] D. C. Popescu, M. M. J. Smulders, B. P. Pichon, N. Chebotareva, S.-Y. Kwak, O. L. J. van Asselen, R. P. Sijbesma, E. DiMasi, N. A. J. M. Sommerdijk, J. Am. Chem. Soc. 2007, 129, 14058-14067.

[16] S. Weiner, I. Sagi, L. Addadi, Science 2005, 309, 1027-1028.

[17] a) E. Loste, F. C. Meldrum, Chem. Commun. 2001, 901-902; b) J. Aizenberg, D. A. Muller, J. L. Grazul, D. R. Hamann, Science 2003, 299, 1205-1208.

[18] E. M. Pouget, P. H. H. Bomans, J. Goos, P. M. Frederik, G. de With, N. Sommerdijk, Science 2009, 323, 1455-1458.

[19] E. M. Pouget, P. H. H. Bomans, A. Dey, P. M. Frederik, G. de With, N. Sommerdijk, J. Am. Chem. Soc. 2010, 132, 1156011565.

[20] A. Gal, K. Kahil, N. Vidavsky, R. T. DeVol, P. Gilbert, P. Fratzl, S. Weiner, L. Addadi, Adv. Funct. Mater. 2014, 24 , $5420-5426$

[21] P. J. M. Smeets, K. R. Cho, R. G. E. Kempen, N. A. J. M. Sommerdijk, J. J. de Yoreo, Nature Mater. 2015, DOI: 10.1038/ nmat4193.

[22] a) K. Bleek, A. Taubert, Acta Biomater. 2013, 9, 6283; b) O. Casse, O. Colombani, K. Kita-Tokarczyk, A. H. E. Müller, W. Meier, A. Taubert, Faraday Discuss. 2008, 139, 179; c) M. Junginger, K. Bleek, K. Kita-Tokarczyk, J. Reiche, A. Shkilnyy, F. Schacher, A. H. E. Müller, A. Taubert, Nanoscale 2010, 2, 2440; d) M. Junginger, K. Kita-Tokarczyk, T. Schuster, J. Reiche, F. A. Schacher, A. H. E. Müller, H. Cölfen, A. Taubert, Macromol. Biosci. 2010, 10, 1084; e) M. Junginger, C. Kübel, F. H. Schacher, A. H. E. Müller, A. Taubert, $R S C A d v$. 2013,
3, 11301; f) R. Löbbicke, M. Chanana, H. Schlaad, C. PilzAllen, C. Günter, H. Möhwald, A. Taubert, Biomacromolecules 2011, 12, 3753; g) S. Schweizer, A. Taubert, Macromol. Biosci. 2007, 7, 1085; h) A. Shkilnyy, J. Brandt, A. Mantion, O. Paris, H. Schlaad, A. Taubert, Chem. Mater. 2009, 21, 1572; i) A. Shkilnyy, A. Friedrich, B. Tiersch, S. Schöne, M. Fechner, J. Koetz, C.-W. Schläpfer, A. Taubert, Langmuir 2008, 24, 2102; j) A. Shkilnyy, R. Gräf, B. Hiebl, A. T. Neffe, A. Friedrich, J. Hartmann, A. Taubert, Macromol. Biosci. 2009, 9, 179; k) A. Shkilnyy, S. Schöne, C. Rumplasch, A. Uhlmann, A. Hedderich, A. Taubert, Colloid Polym. Sci. 2011, 289, 881.

[23] A. Dey, P. H. H. Bomans, F. A. Mueller, J. Will, P. M. Frederik, G. de With, N. A. J. M. Sommerdijk, Nature Mater. 2010, 9, $1010-1014$.

[24] J. M. Galloway, S. S. Staniland, J. Mater. Chem. 2012, 22, 12423-12434.

[25] J. H. Fendler, F. C. Meldrum, Adv. Mater. 1995, 7, 607-632.

[26] B. Bayerlein, P. Zaslansky, Y. Dauphin, A. Rack, P. Fratzl, I. Zlotnikov, Nat. Mater. 2014, 13, 1102-1107.

[27] N. A. J. M. Sommerdijk, M. Cusack, Nature Mater. 2014, 13, 1078-1079.

[28] D. Wacey, M. Saunders, M. Roberts, S. Menon, L. Green, C. Kong, T. Culwick, P. Strother, M. D. Brasier, Sci. Rep. 2014, 4, 5841.

[29] A. Negron-Mendoza, S. Ramos-Bernal in Origins, Vol. 6 (Ed.: J. Seckbach), 2005, pp. 181-194.

[30] J.-F. Lambert, Origins Life Evol. Biospheres 2008, 38, 211.

[31] M. Jaber, J.-F. Lambert, J. Phys. Chem. Lett. 2010, 1, 85.

[32] a) J. P. Ferris, A. R. Hill, R. H. Liu, L. E. Orgel, Nature 1996, 381, 59-61; b) M. M. Hanczyc, S. M. Fujikawa, J. W. Szostak, Science 2003, 302, 618-622.

[33] D. Yang, S. Peng, M. R. Hartman, T. Gupton-Campolongo, E. J. Rice, A. K. Chang, Z. Gu, G. Q. Lu, D. Luo, Sci. Rep. 2013, 3, 3165.

[34] J. H. Choy, S. Y. Park, J. S. Jeong, Y. J. Portier, J. Am. Chem. Soc. 1999, 121, 1399-1400.

[35] M. A. Thyveetil, P. V. Coveney, H. C. Greenwell, J. L. Suter, J. Am. Chem. Soc. 2008, 130, 4742-4756.

[36] R. M. R. Bull, C. Markland, G. R. Williams, D. O'Hare, J. Mater. Chem. 2011, 21, 1822-1828.

[37] K. Ladewig, Z. P. Xu, G. Q. Lu, Expert Opin. Drug Delivery 2009, 6, 907-922.

[38] R. Liang, R. Tian, L. Ma, L. Zhang, Y. Hu, J. Wang, M. Wei, D. Yan, D. G. Evans, X. Duan, Adv. Funct. Mater. 2014, 24, 3144-3151.

[39] M. Merchán, T. S. Ouk, P. Kubát, K. Lang, C. Coelho, V. Verney, S. Commereuc, F. Leroux, V. Sol, C. Taviot-Guého, J. Mater. Chem. B 2013, 1, 2139-2146.

[40] H. M. Kim, K. M. Kim, B. C. Jung, Y. S. Kim, J. H. Choy, J. M. Oh, Adv. Mater. 2014, 26, 1582-1589.

[41] G. Choi, O. J. Kwon, Y. Oh, C. O. Yun, J. H. Choy, Sci. Rep. 2014, 4, DOI: $10.1038 /$ srep04430.

[42] S. J. Choi, J. M. Oh, H. E. Chung, S. E. Hong, I. H. Kim, J. H. Choy, Current. Pharm. 2013, 19, 7196-7202.

[43] Y. S. Gao, J. W. Wu, Q. Wang, C. A. Wilkie, D. O'Hare, J. Mater. Chem. A 2014, 2, 10996-11016.

[44] a) H. Hintze-Brüning, F. Leroux, T. Stimpfling, P. Keil, H. Theil, Vol. WO 2014111539 A1, 2014; 2014; b) F. Leroux, T. Stimpfling, H. Hintze-Bruening, Recent Pat. Nanotechnol. 2012, 6, 238-248.

[45] R. Z. Liang, D. P. Yan, R. Tian, X. J. Yu, W. Y. Shi, C. Y. Li, M. Wei, D. G. Evans, X. Duan, Chem. Mater. 2014, 26, 25952600.

[46] a) N. P. Funnell, Q. Wang, L. Connor, M. D. Tucker, D. O'Hare, A. L. Goodwin, Nanoscale 2014, 6, 8032-8036; b) J. B. Liang, R. Z. Ma, N. Iyi, Y. Ebina, K. Takada, T. Sasaki, Chem. Mater. 2010, 22, 371-378; c) R. Ma, M. Osada, L. F. Hu, T. Sasaki, Chem. Mater. 2010, 22, 6341-6346; d) R. Z. Ma, T. Sasaki, Adv. Mater. 2010, 22, 5082-5104; e) M. F. Shao, M. Wei, D. Evans, G. X. Duan, Chem. Eur. J. 2013, 19, 4100-4108. 
[47] a) R. Ma, J. B. Liang, X. H. Liu, T. Sasaki, J. Am. Chem. Soc. 2012, 134, 19915-19921; b) J. L. Gunjakar, I. Y. Kim, J. M. Lee, Y. K. Jo, S. J. Hwang, J. Phys. Chem. C 2014, 118, 38473863.

[48] R. Ma, X. H. Liu, J. B. Liang, Y. Bando, T. Sasaki, Adv. Mater. 2014, 26, 4173-4178.

[49] J. W. Zhao, J. Chen, S. M. Xu, M. F. Shao, Q. Zhang, F. Fei, J. Ma, M. Wei, D. G. Evans, X. Duan, Adv. Funct. Mater. 2014, 24, 2938-2946.

[50] Z. Jiang, Z. H. Li, Z. H. Qin, H. Y. Sun, X. L. Jiao, D. R. Chen, Nanoscale 2013, 5, 11770-11775.

[51] T. Stimpfling, F. Leroux, Chem. Mater. 2010, 22, 974-987.

[52] F. Song, X. Hu, Nature Commun. 2014, 5, DOI: 10.1038/ ncomms5477.

[53] J. L. Gunjakar, T. W. Kim, H. N. Kim, I. Y. Kim, S. J. Hwang, J. Am. Chem. Soc. 2011, 133, 14998-15007.

[54] C. G. Silva, Y. Bouizi, V. Fornés, H. Garcia, J. Am. Chem. Soc. 2009, 131, 13833-13839.

[55] M. F. Shao, F. Y. Ning, M. Wei, D. G. Evans, X. Duan, $A d v$. Funct. Mater. 2014, 24, 580-586.

[56] E. Coronado, C. Martí-Gastaldo, E. Navarro-Moratalla, A. Ribera, S. J. Blundell, P. J. Baker, Nature Chem. 2010, 2, 10311036.

[57] G. Abellán, E. Coronado, C. Martí-Gastaldo, A. Ribera, J. L. Jordá, H. García, Adv. Mater. 2014, 26, 4156-4162; G. Abellan, J. L. Jorda, P. Atienzar, M. Varela, M. Jaafar, J. Gomez-Herrero, F. Zamora, A. Ribera, H. Garcia, E. Coronado, Chem. Sci 2014, DOI: 10.1039/C1034SC03460K.

[58] a) W. Fujita, K. Awaga, T. Yokoyama, Inorg. Chem. 1997, 36, 196-199; b) J. R. Neilson, B. Schwenzer, R. Seshadri, D. E. Morse, Inorg. Chem. 2009, 48, 11017.

[59] a) R. H. Colman, C. Ritter, A. S. Wills, Chem. Mater. 2008, 20, 6897; b) E. A. Nytko, M. P. Shores, J. S. Helton, D. G. Nocera, Inorg. Chem. 2009, 48, 7782; c) R. H. Colman, A. Sinclair, A. S. Wills, Chem. Mater. 2010, 22, 5774-5779.

[60] a) S. Chu, T. M. McQueen, R. Chisnell, D. E. Freedman, P. Müller, Y. S. Lee, D. G. Nocera, J. Am. Chem. Soc. 2010, 132,
5570-5571; b) D. E. Freedman, T. H. Han, A. Prodi, P. Müller, Q. Z. Huang, Y. S. Chen, S. M. Webb, Y. S. Lee, T. M. McQueen, D. G. Nocera, J. Am. Chem. Soc. 2010, 132, 16185.

[61] a) P. Rabu, M. Drillon, K. Awaga, W. Fujita, T. Sekine in Magnetism: Molecules to Materials II. Molecule-Based Materials (Eds.: J. S. Miller, M. Drillon), Wiley-VCH, Weinheim, 2001, pp. 357-395; b) G. Rogez, C. Massobrio, P. Rabu, M. Drillon, Chem. Soc. Rev. 2011, 40, 1031-1058.

[62] J.-M. Rueff, J.-F. Nierengarten, P. Gilliot, A. Demessence, O. Crégut, M. Drillon, P. Rabu, Chem. Mater. 2004, 16, 2933 2937.

[63] H. Shimizu, M. Okubo, A. Nakamoto, M. Enomoto, N. Kojima, Inorg. Chem. 2006, 45, 10240-10247.

[64] E. Delahaye, S. Eyele-Mezui, M. Diop, C. Leuvrey, P. Rabu, G. Rogez, Dalton Trans. 2010, 39, 10577-10580.

[65] R. Mas-Balleste, C. Gomez-Navarro, J. Gomez-Herrero, F. Zamora, Nanoscale 2011, 3, 20-30.

[66] D. Schrijvers, F. Leroux, V. Verney, M. Patel, Green Chem. 2014, 16, 4969-4984.

[67] a) Z. Qian, R. Li, X. Zhao, S. Hou, S. Sanvito, Phys. Rev. B (Condensed Matter and Materials Physics) 2008, 78, 113301; b) A. M. Mahmoud, A. J. Bergren, N. Pekas, R. L. McCreery, Adv. Funct. Mater. 2011, 21, 2273; c) S. Shi, G. Schmerber, J. Arabski, J.-B. Beaufrand, D. J. Kim, S. Boukari, M. Bowen, N. T. Kemp, N. Viart, G. Rogez, E. Beaurepaire, H. Aubriet, J. Petersen, C. Becker, D. Ruch, Appl. Phys. Lett. 2009, 95; d) Y. Don Park, J. A. Lim, H. S. Lee, K. Cho, Mater. Today 2007, $10,46-54$.

[68] a) V. Dediu, L. E. Hueso, I. Bergenti, A. Riminucci, F. Borgatti, P. Graziosi, C. Newby, F. Casoli, M. P. De Jong, C. Taliani, Y. Zhan, Phys. Rev. B 2008, 78, 115203; b) L. Hueso, I. Bergenti, A. Riminucci, Y. Zhan, V. Dediu, Adv. Mater. 2007, 19, 2639; c) M. Pauly, J.-F. Dayen, D. Golubev, J.-B. Beaufrand, B. P. Pichon, B. Doudin, S. Bégin-Colin, Small 2012, 8, 108115; d) A. Fert, Angew. Chem. Int. Ed. 2008, 47, 5956-5967; Angew. Chem. 2008, 120, 6042.

Received: February 16, 2015 